Development of the headspace Family and Friends Satisfaction Scale: findings from a pilot study

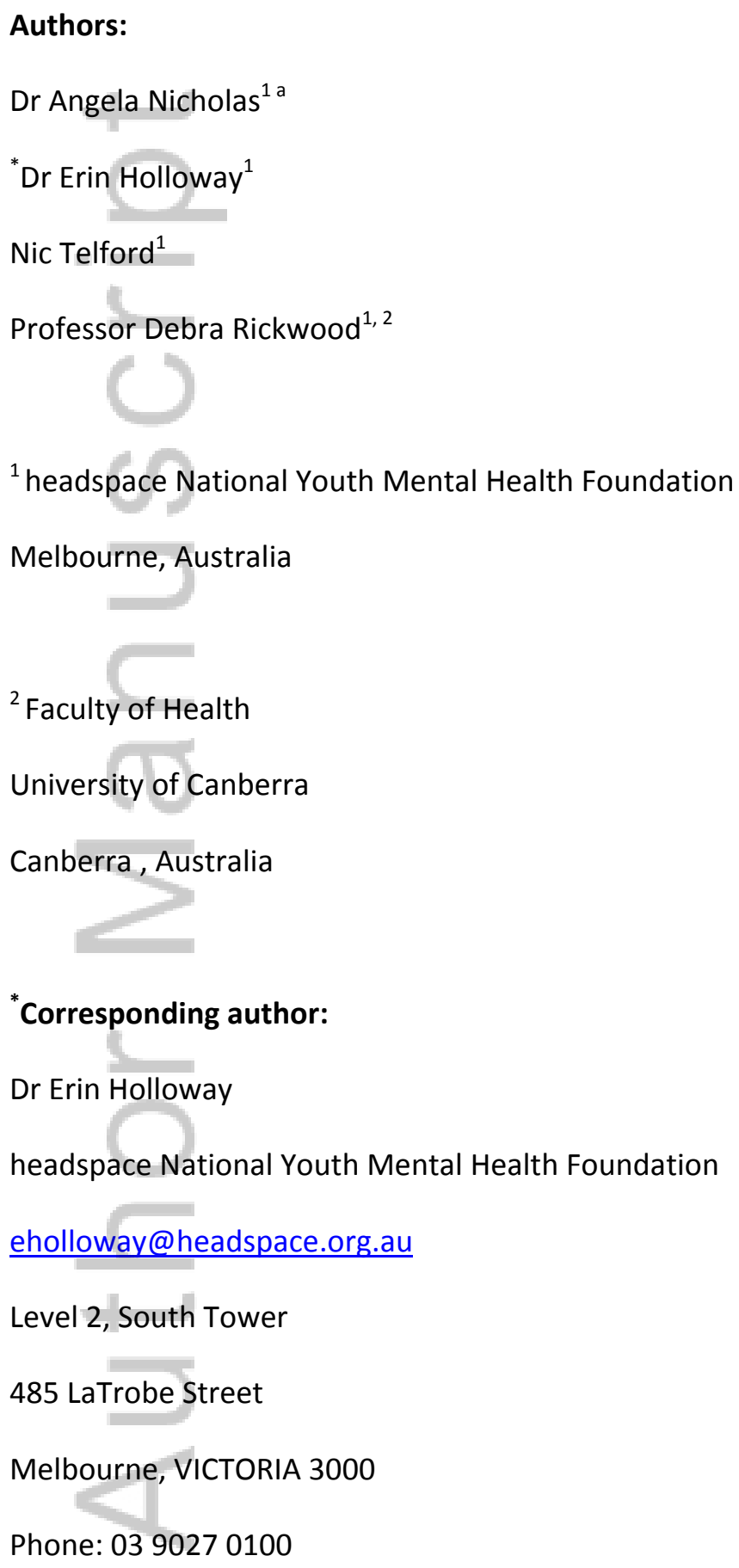

${ }^{*}$ Corresponding author:

Dr Erin Holloway

headspace National Youth Mental Health Foundation

eholloway@headspace.org.au

Level 2, South Tower

485 LaTrobe Street

Melbourne, VICTORIA 3000

Phone: 0390270100

This is the author manuscript accepted for publication and has undergone full peer review but has not been through the copyediting, typesetting, pagination and proofreading process, which may lead to differences between this version and the Version of Record. Please cite this article as doi: $10.1111 /$ eip.12427

This article is protected by copyright. All rights reserved. 


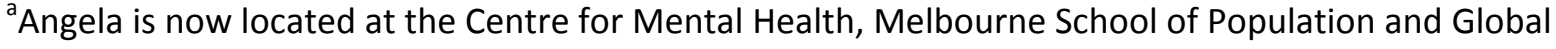
Health, The University of Melbourne, Level 4, 207 Bouverie Street, Carlton 3010, Victoria, Australia

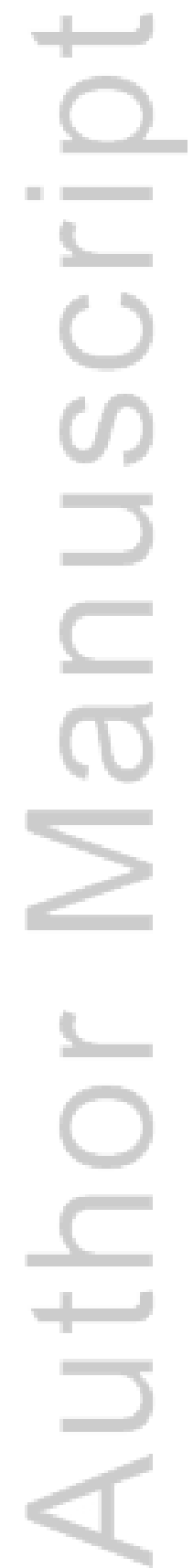

This article is protected by copyright. All rights reserved. 


\section{Development of the headspace Family and Friends Satisfaction Scale: findings from a pilot study}

Aims The primary aim of this pilot study was to determine the psychometric properties of the 18item headspace Family and Friends Satisfaction Scale (hFAFSS).

Methods During August 2015, staff from 22 headspace centres approached family members and friends of young people attending headspace to complete the hFAFSS. Principal components analysis with oblique Promin rotation and polychoric correlations were used to assess the factor structure of the hFAFSS.

Results There were 277 usable responses. Satisfaction was high, resulting in little variance. Parallel analyses suggested that the scale items tapped a single factor (68\% of variance).

Conclusions This study is one of the first attempts to measure the satisfaction of family and friends with primary care-based youth mental health services. Satisfaction of family members and friends was shown to be high, but limited variance restricts the usability of the hFAFSS as an evaluation measure, and revision and further testing is needed.

Keywords: adolescent; family; mental health; personal satisfaction; surveys and questionnaires

\section{Introduction}

headspace, Australia's National Youth Mental Health Foundation, provides youth-friendly mental health and health services to 12 -to-25 year olds from around 100 centres across Australia through a primary care, early intervention platform. headspace routinely collects service satisfaction data from young people to improve service quality. ${ }^{1,2}$ Parents and caregivers offer a unique perspective from that of the young people, with studies reporting low to moderate correlations ( $r=.19$ to .31 ) between the views of young people and their parents or caregivers on service satisfaction. ${ }^{3-5} Y e t$, service satisfaction of parents and caregivers can affect future help-seeking and service utilisation for the young person, ${ }^{6,7}$ and their attitudes and expectations can affect service engagement, ${ }^{8}$ dropout ${ }^{9}$ and treatment outcomes. ${ }^{10}$ Assessing satisfaction among family members and friends of headspace service users and responding to feedback is, therefore, essential.

This study involved pilot testing the purpose-designed headspace Family and Friends Satisfaction Questionnaire (hFAFSS). No suitable questionnaire was available from the literature, as most 
targeted child and adolescent mental health services or acute care settings. A measure was needed that was relevant to primary care youth mental health settings and that tapped similar constructs to those measured for the young people accessing the service. ${ }^{1}$ The specific aims of this study were to determine:

- the psychometric properties of the hFAFSS;

- whether respondents found the hFAFSS to be understandable, acceptable and comprehensive; and

- the current level of satisfaction of family members and friends with headspace centre services.

\section{Method}

\section{Development of the headspace family and friends satisfaction survey}

To develop the hFAFSS, wording from the 14-item headspace Youth (mental health) Service Satisfaction Scale (YSSS), ${ }^{1,2}$ was adapted for family and friends. Four further items were added following a review of existing family satisfaction questionnaires and consultation with the headspace Youth National Reference Group, family and friends reference group, and headspace centre staff (see Table 2 for the resulting 18 items and five proposed subscales). Responses are provided on a five-point scale from 'Strongly disagree' (1) to 'Strongly agree' (5); some items allow a 'Not applicable' or 'I don't know'.

Demographic questions captured characteristics of both the family member or friend respondent and the young person attending headspace for whom they provide support. To assess usability and face validity of the hFAFSS, three open-ended questions were included asking if respondents would like additional questions and if any questions were difficult to understand or inappropriate to ask.

\section{Participants and setting}

Twenty-one headspace centres from across Australia, and representing a mix of metro and regional, participated. Data collection occurred in August 2015, when staff were encouraged to ask family members and friends attending their centre to complete the hFAFSS. Advertising posters were also placed in waiting rooms.

\section{Procedure}

This article is protected by copyright. All rights reserved. 
This study was approved as a Quality Assurance/Negligible risk research project by the Melbourne Health Human Research Ethics Committee (QA2015098).

Participants were offered an online version of the hFAFSS for completion on a headspace iPad or their own device. Alternatively, they completed an anonymous paper copy returned to a box in the waiting room. Hard copies were returned to the headspace Research and Evaluation team, who entered responses.

\section{Data analysis}

Data analysis was conducted using IBM SPSS v.23 and FACTOR. Thematic analysis was applied to free text responses using NVivo.

Descriptive statistics were calculated for demographics and for each scale item.

The ordinal nature of the satisfaction data was addressed using principal components analysis (PCA) with an oblique Promin rotation ${ }^{11}$ and polychoric correlations to assess the hFAFSS's factor structure. Parallel analysis was used to determine the number of factors extracted. ${ }^{12}$

To deal with 'NA'/'Don't know' responses, which made up $8 \%$ of the total data, two methods were used for comparison. The first method removed cases with 8 or more 'NA'/'Don't know' responses and the remaining 'NA/Don't know' responses were replaced using multiple imputation (5 imputations; $n=235$ ). In the second method, all cases containing 'NA'/'Don't know' responses were removed $(n=121)$. Analyses conducted on all datasets revealed equivalent results for all analyses; results for the larger sample with imputed missing values are reported.

A multiple regression analysis using demographic variables (Table 1 ) to predict total satisfaction was conducted. A one-way analysis of variance (ANOVA) with Tukey's (HSD) post hoc test was conducted to determine if the number of sessions attended by the young person was related to family/friend satisfaction.

\section{Results}

This article is protected by copyright. All rights reserved. 
Twenty-one headspace centres provided questionnaires (range, 2-56 questionnaires per centre). From an initial 296 questionnaires, nineteen cases were missing between $39 \%$ and $100 \%$ of items on the hFAFSS and were excluded. Four cases had missing data on one item and replaced using multiple imputation.

Demographic characteristics of respondents and the young people they support (mean age $=15.87$, range $=11-25, S D=3.08)$ are shown in Table 1.

\section{INSERT TABLE 1 ABOUT HERE}

Table 2 shows descriptive statistics for each hFAFSS item. Items in the 'Satisfaction with help provided' and 'Satisfaction with your involvement' subscales had a high number of 'Don't know/NA' responses. Thematic analysis of free-text responses suggested that it was too early in the episode of care for them to confidently answer some items.

Descriptive statistics reveal high mean satisfaction scores, little variance, and high negative skew and kurtosis (Table 2); consequently, polychoric correlations were used to assess the structure of the hFAFSS. ${ }^{12}$ A significant Bartlett's test $(p<.001)$ and good Kaiser-Meyer-Olkin statistic of $.93{ }^{13}$ were obtained. Parallel analyses based on Minimum Rank Factor Analysis (MRFA) ${ }^{14}$ and on PCA ${ }^{15}$ both suggested a one-factor solution. The polychoric correlation matrices showed a one-factor model explaining $68 \%$ of variance, and a two-factor model explained an additional $8 \%$. Consequently, total satisfaction scores were computed as an average of valid items, yielding a scale ranging from 1 to 5 with higher scores indicating higher satisfaction. Internal reliability of the one-factor model revealed excellent reliability: ordinal alpha $=.95$.

\section{INSERT TABLE 2 ABOUT HERE}

Multiple regression analysis of the demographic variables revealed that these did not significantly predict variance in total satisfaction scores $\left(F(5,263)=0.55, p>.05, R_{\text {adjusted }}^{2}=.008\right)$. An ANOVA assessing the relationship between number of sessions and total satisfaction was significant $(F(4$, $254)=8.18, p<.001)$ with satisfaction scores for those who had attended 8 or more sessions $(M=$ 4.51) being significantly higher $(p<.001)$ than those who had attended 1 or 2 sessions $(M=4.03)$. 


\section{Discussion}

Family members and friends expressed a high level of satisfaction with all aspects of headspace services measured. Qualitative responses suggest the hFAFSS is acceptable, usable and comprehensive, with the exception for those whose young person had attended a small number of sessions. This group had a higher number of 'NA/Don't know' responses and lower average satisfaction scores. The high number of 'NA/Don't know' responses for the item 'headspace linked me to other information or services when I needed them for myself', raises questions about the utility of this item.

Consistent with previous research, participants were most commonly mothers. ${ }^{4}{ }^{16}$ Also consistent with previous research, neither the demographics of the family member or friends completing the questionnaire, nor of the young person they support, predicted parent or caregiver satisfaction. ${ }^{4,5}$

Results of the factor analysis indicate that the hFAFSS items measure one general satisfaction construct, as was the case when the headspace youth satisfaction measure (YSSS) was first piloted. ${ }^{2}$ However, with replication in a much larger sample size, the youth measure was shown to have a four-factor solution. ${ }^{1}$ It may be that similar results would be found for the hFAFSS with future largerscale testing.

While invariance is frequently noted in the satisfaction literature, it is rarely practically addressed. ${ }^{4,19}$ Low variance increases risk of type II error, ${ }^{17}$ incorrect model selection, and biased parameter estimation. ${ }^{18}$ It is of benefit to both headspace services and the broader mental health field to identify factors associated with family and friends' satisfaction and, therefore, revision and retesting of the hFAFSS is required. One approach to increasing variance is to use a Positive-Packed Rating Scale, ${ }^{17,} 19$ shifting 'middle responses' down the response scale, and expanding the more positive response options. ${ }^{19}$ For example, in addition to the existing 'Agree' and 'Strongly Agree' options, the hFAFSS could include an additional 'Somewhat Agree' option.

While high scores can reflect a genuinely high level of satisfaction, they can also result from response bias ${ }^{19}$ or sampling error. It is possible that the headspace centre-based recruitment method produced bias by sampling only family and friends who were most engaged and satisfied. Alternative recruitment methods such as online platforms and including all headspace centres, will be considered in the future to access a broader range of respondents. 
The current study highlights both the importance and the challenges of measuring satisfaction among family members and friends for youth mental health services. The development of a psychometrically sound scale will allow youth services to regularly assess the satisfaction of family and friends for continued service improvement. Further, it enables the examination of factors which may predict treatment outcomes for young people, and the role that engagement of family and friends has in achieving positive change for young clients.

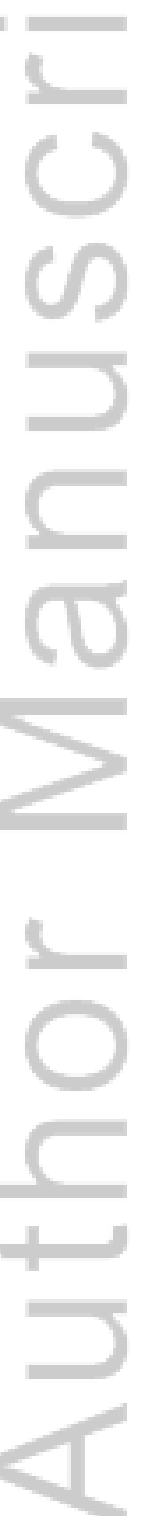

This article is protected by copyright. All rights reserved. 


\section{References}

1. Rickwood D, Nicholas A, Mazzer K, Telford N, Parker A, Tanti C, et al. Satisfaction with youth mental health services: further scale development and findings from headspace - Australia's National Youth Mental Health Foundation. Early Interv Psychiatry. 2015.

2. Simmons MB, Parker AG, Hetrick SE, Telford N, Bailey A, Rickwood D. Development of a satisfaction scale for young people attending youth mental health services. Early Interv Psychiatry. 2014;8:382-6.

3. Athay MM, Bickman L. Development and psychometric evaluation of the youth and caregiver Service Satisfaction Scale. Adm Policy Ment Health. 2012;39:71-7.

4. Garland AF, Haine RA, Boxmeyer CL. Determinates of youth and parent satisfaction in usual care psychotherapy. Eval Program Plann. 2007;30:45-54.

5. Godley SH, Funk RR, Fiedler EM. Consumer Satisfaction of Parents and Their Children with Child/Adolescent Mental Health Services. Evaluation and Program Planning. 1998;21:31-45.

6. Tung W-C, Jie Hu. Factors Related to Family Caregivers' Satisfaction With Home Care for Mental Illness in Taiwan. Home Health Care Management \& Practice. 2010;22:479-84.

7. Morrissey-Kane E, Prinz RJ. Engagement in child and adolescent treatment: the role of parental cognitions and attributions. Clinical Child And Family Psychology Review. 1999;2:183-98.

8. Brinkmeyer M, Eyberg S, Nguyen M, Adams R. Family engagement, consumer satisfaction and treatment outcome in the new era of child and adolescent in-patient psychiatric care. Clinical Child Psychology and Psychiatry. 2004;9:553-66.

9. Kazdin AE, Holland L, Crowley M, Breton S. Barriers to Treatment Participation Scale: evaluation and validation in the context of child outpatient treatment. J Child Psychol Psychiatry. 1997;38:1051-62.

10. Kazdin A, Wassell G. Therapeutic Changes in Children, Parents, and Families Resulting From Treatment of Children With Conduct Problems. Journal of the American Academy of Child \& Adolescent Psychiatry. 2000;39:414-20.

11. Lorenzo-Seva U. Promin: a method for oblique factor rotation. Multivariate Behavioral Research. 1999;34:347-56.

12. Baglin J. Improving Your Exploratory Factor Analysis for Ordinal Data: A Demonstration Using FACTOR. Practical Assessment, Research \& Evaluation [Internet]. 2014; 19(5). Available from: http://pareonline.net/getvn.asp?v=19\&n=5.

13. Beavers A, Lounsbury J, Richards J, Huck S, Skolits G, Esquivel S. Practical Considerations for Using Exploratory Factor Analysis in Educational Research. Practical Assessment, Research \& Evaluation [Internet]. 2013; 18(6). Available from: http://pareonline.net/getvn.asp?v=18\&n=6.

14. Timmerman M, Lorenzo-Seva U. Dimensionality Assessment of Ordered Polytomous Items with Parallel Analysis. Psychological Methods. 2011;16:209-20.

15. Horn J. A rationale and test for the number of factors in factor analysis. Psychometrika. 1965;30:179-85.

16. Aarons GA, Covert J, Skriner LC, Green A, Marto D, Garland AF, et al. The eye of the beholder: youths and parents differ on what matters in mental health services. Adm Policy Ment Health. 2010;37:459-67.

17. Hessling R, Traxel N, Schmidt T. Ceiling Effect. In: Lewis-Beck M, Bryman A, Liao T, editors. Encyclopedia of Social Science Research Methods. Thousand Oaks: SAGE Publications, Inc; 2004.

18. Wang L, Zhang Z, McArdle J, Salthouse T. Investigating Ceiling Effects in Longitudinal Data Analysis. Multivariate Behavioral Research. 2009;43:476-96.

19. Masino C, Lam T. Choice of rating scale labels: implication for minimizing patient satisfaction response ceiling effect in telemedicine surveys. Telemedicine and e-Health. 2014;20:1150-5. 


\section{University Library}

\section{- M M N E R VA A gateway to Melbourne's research publications}

Minerva Access is the Institutional Repository of The University of Melbourne

\section{Author/s:}

Nicholas, A;Holloway, E;Telford, N;Rickwood, D

Title:

Development of the headspace Family and Friends Satisfaction Scale: Findings from a pilot study.

\section{Date:}

2018-06

\section{Citation:}

Nicholas, A., Holloway, E., Telford, N. \& Rickwood, D. (2018). Development of the headspace Family and Friends Satisfaction Scale: Findings from a pilot study.. Early Interv Psychiatry, 12 (3), pp.478-482. https://doi.org/10.1111/eip.12427.

Persistent Link:

http://hdl.handle.net/11343/292784 